\title{
Comparison of IDRS, ADA and FINDRISC Diabetes Risk Assessment Tools: A Cross-Sectional Analysis in a Tertiary Care Hospital.
}

\author{
Dr. Nazma Akter ${ }^{1}$, Dr. Nazmul Kabir Qureshi ${ }^{2}$ \\ ${ }^{1}$ Department of Medicine, MARKS Medical College \& Hospital, Dhaka, Bangladesh \\ ${ }^{2}$ National Health Care Network (NHN), Uttara Executive Centre, Dhaka, Bangladesh
}

\section{Abstract}

\section{Background}

To identify individuals at high risk of developing type 2 diabetes mellitus (T2DM), the use of a validated risk-assessment tool is currently recommended. A simple risk-assessment scoring system will be beneficial to identify the high-risk adults and thus taking adequate preventive measures in combating DM.

Aim

The aim of this study was to examine the results of three commonly used validated risk-assessment tools when applied to the same population.

Method

This cross-sectional study was carried out with randomly sampled 602 non-diabetic adults visiting the outpatient department (OPD) of a tertiary care hospital in Dhaka, Bangladesh from January to December 2019. The Indian Diabetes Risk Score (IDRS), American Diabetes Association (ADA) Risk Score and Finish Diabetes Risk Score (FINDRISC) questionnaires were used to calculate the predicted risk score for developing T2DM within 10 years.

Results

There were 602 subjects and $55.0 \%$ were females. The mean $( \pm \mathrm{SD})$ age of the study subjects was $38.56 \pm 1.13$ years. IDRS categorized $38.2 \%$ of individuals at 'high risk' of developing diabetes followed by ADA (22.4\%) and the FINDRISC (8.6 \%); $[\mathrm{p}<0.05]$.

\section{Conclusions}

The adoption of a different valid risk assessment tools can alter the predicted risk of an individual for the development of diabetes. Therefore, it is important to validate these risks scoring systems for each population considered. (SJDEM 2020/ Vol 10/No 2)

Keywords: Diabetes Risk Assessment Score, IDRS, ADA Diabetes Risk assessment Tools, FINDRISC

Correspondence email: nazma_aktar_endo@yahoo.com

ORCID ID: https://orcid.org/0000-0003-0830-0748

Copyright: This is an open-access article distributed under the terms of the Creative Commons Attribution License, which permits unrestricted use, distribution, and reproduction in any medium, provided the original author and source are credited (CC BY 4.0)

\section{Introduction}

The prevalence of diabetes is rising rapidly throughout the world (1).The studies have demonstrated that early detection of established diabetes improves the outcome, and therefore the intervention programs are typically targeted at individuals at high risk of developing diabetes (2). However, the evidence on the usefulness of population screening with these screening tools is weak ${ }^{(3)}$.

The diabetes prevention trials included people with impaired glucose tolerance, who can be identified only by conducting an oral glucose tolerance test (OGTT) (4). Screening the targeted populations at risk of diabetes with OGTT would increase the yield. However, the economic efficiency of this type of screening is a concern ${ }^{(5)}$. Thus, finding simpler, more pragmatic methods to identify individuals at high risk of progression to diabetes and who might benefit from targeted prevention is an important goal. Multivariate risk scores that have been developed in recent years to predict diabetes risk for healthy individuals, which are recommended in current guidelines for diabetes prevention programs in some countries $(6,7)$.Some scoring systems have been validated in selected populations, prompting their use in other countries $(8,9$.$) Nevertheless,$ recent studies have shown that the risk scores that are developed in the same country can lead to different results ${ }^{(10)}$.

The prevalence of diabetes is increasing in Bangladesh in both urban and rural areas (11). This epidemiological change can 
increase healthcare use and expenditure and can impose a huge economic burden on the healthcare systems. However, screening the adult population with these scoring systems and the evidence related to the use of these scoring systems in Bangladesh is limited. The current study aims to compare the results of three commonly used validated risk-assessment tools for predicting type 2 diabetes when applied to the same population attending the outpatient department of a tertiary care hospital.

\section{Methods}

\section{Study design and patient population}

This cross-sectional analytical study was conducted among randomly sampled 602 adult Bangladeshi male \& female subjects. The study population consisted of non-diabetic adults visiting the outpatient department (OPD) of Medicine, MARKS Medical College \& Hospital, a tertiary care hospital in Dhaka, Bangladesh from January to December 2019. Individuals with known type 1 or type 2 diabetes or any endocrine illness and with an apparent communicative, cognitive impairment or physical disability were excluded from the study. Subjects having a previous history of high blood glucose during pregnancy or other health examination were also included.

With written informed consent, data including demographicanthropometric and clinical characteristics and different risk factors of an individual subject that are necessary to calculate the predicted risk score for developing T2DM within the next 10 years, using the Indian Diabetes Risk Score (IDRS), American Diabetes Association (ADA) Risk Score and Finish Diabetes Risk Score (FINDRISC), were gathered using a questionnaire.

\section{Risk Assessment Scores}

There has not been a previously validated risk scoring system for Bangladesh population. After a review of validated risk assessment scoring systems for different countries (12-15), we decided to include the Indian Diabetes Risk Score (IDRS) (15), American Diabetes Association (ADA), (12) and Finnish Diabetes Risk Score (FINDRISC) (13) for the risk assessment of our population. The IDRS has a sensitivity of $72.5 \%$ and specificity of $60.1 \%$ and is derived based on the largest population-based study on diabetes in India (15). The ADA developing type 2 diabetes risk tool was well developed and tested for validity and reliability on different population in different countries ${ }^{(16)}$. The FINDRISC risk assessments tool was chosen in this study primarily because it featured in the NICE guidance, ${ }^{(17)}$ and also has some common risk variables that make direct comparisons feasible.

\section{Methods of calculation of Risk Score}

Anthropometric measurements of height and weight were measured by a reliable height scale and weighing scale, respectively. According to the Body Mass Index (BMI): weight in kilograms/square of height in meters $(\mathrm{kg} / \mathrm{m} 2)$, the patients were categorized as underweight $(\leq 18.5 \mathrm{~kg} / \mathrm{m} 2)$, normal weight (BMI: $<25 \mathrm{~kg} / \mathrm{m} 2$ ), overweight (BMI: $25-<30 \mathrm{~kg} / \mathrm{m} 2$ ), obese (BMI: $\geq 30-<40 \mathrm{~kg} / \mathrm{m} 2$ ) and morbid obese (BMI: $\geq 40$ $\mathrm{kg} / \mathrm{m} 2$ ) (18). The waist circumference (WC) was measured in a horizontal plane, midway between the inferior margin of the ribs and the superior border of the iliac crest using a reliable measuring inch tape. Hypertension was defined as a systolic blood pressure $\geq 140 \mathrm{mmHg}$ and/or diastolic blood pressure $\geq 90 \mathrm{mmHg}\left({ }^{(19)}\right.$. The blood pressure was measured by a manual sphygmomanometer in standard conditions (measured 2 times after a 5-min rest between each measurement)(20). All the participants were assessed with IDRS, FINDRISC and ADA risk score.

\section{IDRS system:}

The IDRS system uses four parameters (age, waist circumference, physical activity and family history) to assess the risk of developing T2DM (21). Subjects with an IDRS of $<30$ was categorized as low risk, $30-50$ as moderate risk and those with $>60$ as high risk for developing diabetes.

\section{ADA Risk score:}

The ADA risk score system has seven risk factors (the age, sex, BMI, physical activity, history of gestational diabetes, family history and history of hypertension) correlating with the risk of developing T2DM(22).When the score is 5 or more; it is considered that the particular person is at an increased risk of developing type 2 diabetes.

\section{FINDRISC system}

The FINDRISC considers 8 risk factors (age, family history, WC, BMI, daily physical activity, vegetable/fruit diet, history of hypertension, and a history of high blood glucose) to assess the risk of developing $\mathrm{T}_{2} \mathrm{DM}^{(23)}$. It demonstrates the probability of developing T2DM within the next 10 years and the risk score is categorized as $<7$ : low, 7-11: slightly elevated, 12-14: moderate, 15-20: high and $>20$ : very high.

\section{Statistical analysis}

Data were analyzed with Statistical Package for Social Science (SPSS Inc, Chicago, Illinois, USA) software version 16. The means and standard deviations were used to describe continuous data. For categorical data, frequencies and percentages were estimated. Categorical variables were compared with each other using the chi-square test. $\mathrm{P}$ value $<0.05$ was considered as significant.

\section{Results}

\section{Baseline characteristics}

A total of 602 subjects were included in the study. Among them, $45.0 \%$ were male and $55.0 \%$ were female. The mean $( \pm \mathrm{SD})$ age of the study subjects was $38.56 \pm 1.13$ years. The maximum age was 68 years and the minimum was 22 years. Average ( $\pm \mathrm{SD}$ ) body mass index (BMI) was 25.21 \pm $3.67(\mathrm{~kg} / \mathrm{m} 2)$ and waist circumference (WC) was $85.11 \pm 8.45$ $(\mathrm{cm})$. The mean $( \pm \mathrm{SD})$ systolic blood pressure $(\mathrm{SBP})$ of the study subjects was $114.47 \pm 11.58 \mathrm{~mm} \mathrm{Hg}$ and the diastolic blood pressure (DBP) was $75.56 \pm 8.77 \mathrm{~mm} \mathrm{Hg}$ (Table 1). 


\section{Risk assessment factors of IDRS}

According to IDRS tool, $45.0 \%$ of the subjects were below the age of 35 years $[\mathrm{p}=0.39]$. According to the waist circumference grading, the abdominal obesity was higher in females compared to males $(17.1 \%$ vs. $4.7 \%)$; [p $<0.001]$. About $30 \%$ of subjects were engaging with regular exercise or physical activity at home or workplace; $[\mathrm{p}=0.04]$. From this patient population, $29.9 \%$ of subjects had at least 1 parent with diabetes and in $19.4 \%$ of subjects, both parents had diabetes [p=0.38]. (Table2)

\section{Risk assessment factors of ADA}

When it is assessed according to the ADA risk tool, the majority of the subjects $(59.1 \%)$ were from $<40$ years age group; $[\mathrm{p}=0.04]$. A reasonable percentage $(18.73 \%)$ of the female subjects had a history of GDM; [p<0.001]. The majority of the patients $(54.3 \%)$ had a positive family history (mother, father, sister or brother) of DM; [p=0.89] and, $23.8 \%$ of the adults had a history of hypertension; $[\mathrm{p}=0.20]$. The greater majority $(70.8 \%)$ of the adults did not do daily physical activities; [ $\mathrm{p}=0.07]$. Only a minority of the subjects were with normal body weight $(43.5 \%)$, whereas $43.5 \%$ were over-weight and $13.3 \%$ were obese]; [p=0.02]. (Table 3 )

\section{Risk assessment factors of FINDRISC}

According to the FINDRISC tool, most of the subjects $(68.8 \%)$ were from $<45$ years age group; [ $\mathrm{p}=0.93$ ]. The majority $(68.1 \%)$ had a positive family history (parents, grandparents, aunts, uncles etc.) of DM; $[\mathrm{p}=0.90] .29 \%$ of the adults did not do daily physical activities and 36\% did not take vegetables, fruits or berries every day. The majority of the subjects were above the normal body weight (38.5\% were overweight and $12.6 \%$ were obese); $[\mathrm{p}=0.42]$ and a few of them had high abdominal obesity (male vs. female: $3.0 \%$ vs. $13.8 \%$ ); $[\mathrm{p}<0.001]$. Overall, $22.9 \%$ of the adults had hypertension and were on anti-hypertensive medications; $[\mathrm{p}=0.18]$ and $14.6 \%$ had a history of high blood glucose during pregnancy or other health examination; $[\mathrm{p}<0.001]$ (Table 4).

Risk assessment score for type 2 diabetes among studied subjects

According to the IDRS assessment, females were at a higher risk of developing T2DM than male; $[\mathrm{p}<0.001]$ (Table 5). As stated in the IDRS system, $38.2 \%$ of the subjects had a high risk, $47.2 \%$ with moderate risk and $14.6 \%$ with low risk for developing type 2 diabetes; $[\mathrm{p}=0.10]$ (Figure 1).

According to the $\mathrm{ADA}$, the risk of developing type 2 diabetes was higher in male subjects compared to females; $[\mathrm{p}<0.001]$ (Table 5) and a total of $22.4 \%$ of subjects had a high-risk score (DRS $\geq 5$ ) for developing diabetes; $[\mathrm{p}<0.001]$. (Figure 2)

As reported by FINDRISC, the mean risk score was more in female subjects compared to males; $[\mathrm{p}<0.001]$ (Table 5). Only $0.3 \%$ of the subjects had a very high-risk score. However, $8.6 \%$ had high risk, $13.8 \%$ had moderate risk and $36.4 \%$ and mild risk for developing type 2 diabetes; $[\mathrm{p}<0.001]$ (Figure 3).

Difference among three risk score system
In accordance with IDRS tool, $38.2 \%$ of the subjects were in high risk category for developing diabetes (male vs. female: $14.3 \%$ vs. $23.9 \%$ ); $[\mathrm{p}=0.10$ ]. However, the prediction risk of ADA risk tool for the same category was lower $(22.4 \%$; male vs. female: $14.0 \%$ vs. $8.5 \%$ ); $[\mathrm{p}<0.001]$ and risk prediction with FINDRISC scoring system is even lower ( $8.6 \%$; male vs. female: $1.8 \%$ vs. $6.8 \%$ ); [p<0.001] (Table 6).

\section{Discussion}

The systematic reviews have demonstrated the predictive ability of different diabetes risk scoring systems for the development of type 2 diabetes (24). However, these risk scoring systems have been developed in different populations with varying ethnic backgrounds, and the predicted risks can differ considerably between populations. These risks scores have been developed to use readily available information that we gather during routine clinical practice or that can be gathered by questionnaires. Therefore, this is a screening tool that can be utilized with minimum cost than methods of screening involving biochemical measures such as blood glucose.

Computation of diabetes risk based on multivariate risk models is useful in the context of targeting preventive interventions for high-risk groups. Several risk scores have been validated in independent populations, where these have shown good discriminatory ability. Data suggest that the performance of diabetes risk scores are best for the target population ${ }^{25}$, where they will be ultimately be used. Thus, the use of scoring systems for diabetes screening in a different population can be misleading. Whether risk scores enable accurate estimation of absolute risk remains unknown. Therefore, it may also be more useful to develop population-specific risk prediction tools rather than try to find a universal risk score that will work in all populations (26).

In Bangladesh, this is the first study to establish the usefulness of these screening tools in terms of predicting the risk of developing type 2 diabetes in our community. The risk assessments were chosen according to the NICE guidance considerations ${ }^{(17)}$. This study examined whether the adoption of a different validated risk-assessment tool would alter an individual's predicted risk of type 2 diabetes. The main findings from this study demonstrated that the risk of developing type 2 diabetes varies and were dependent on the risk-assessment tool that was used. It was observed that $38.2 \%$ of subjects were predicted to be in the high-risk category when the Indian Diabetes Risk Score was used whereas the ADA risk tool reported 22.4\% and Finish Diabetes Risk Score declared 8.6\% for the same category. These data highlight the inconsistency of the predictive value of these different risk assessment tools.

\section{Conclusion}

Differences were observed in predicted high-risk individuals using different risk assessments tools, and therefore these risk assessment scores should be used with caution when categorizing individuals. This finding suggests that the risk scores should not simply be expected to perform comparably well and may need to be validated within the population in which they are intended to be used. 


\section{Limitation}

The cross-sectional nature of the study, the lack of causal or effect, and the inability to measure the temporal change are the main limitations of this study. This being a study with a smaller number of participants, validation of the risk assessment with a large sample size in different populations would have enhanced the generalizability of the results. Commonly measured biochemical markers such as blood glucose levels are readily available and could have been used as a parameter in risk assessment tools. Use of a risk assessment tool with these parameters could have provided a better risk prediction than with the risk assessment tools that we used for our study.

\section{Future Research Proposal}

We recommend that funding bodies and the journal editors would help to take this agenda forward by viewing the risk score in use as a complex intervention and encouraging more applied research in identifying "high risk" population, using these risk assessment tools that could offer real interventions.
There is a need for a unique diabetes risk assessment tools for Bangladeshi populations. This study would reinforce the development of such national diabetes risk assessment tools and its widespread application in the diabetes screening campaigns.

\section{Acknowledgement}

We thank authorities of MARKS Medical College \& Hospital, for all administrative supports to conduct the study.

\section{Ethical approval:}

The ethical approval was obtained from the ethics review board of the hospital.

\section{Declaration of conflicting interests}

Nothing to declare

\section{Table 1: Comparison of anthropometric $\&$ clinical parameters $(n=602)$}

\begin{tabular}{lccc}
\hline Variables & Male & Female & Total \\
& $($ Mean \pm SD $)$ & $($ Mean \pm SD $)$ & Mean \pm SD $)$ \\
\hline Age $(\mathrm{yrs})$ & $38.88 \pm 1.17$ & $39.30 \pm 1.11$ & $38.56 \pm 1.13$ \\
Height $(\mathrm{m})$ & $1.65 \pm 0.08$ & $1.56 \pm 0.06$ & $1.60 \pm 0.08$ \\
Weight $(\mathrm{kg})$ & $71.17 \pm 1.15$ & $61.49 \pm 1.04$ & $65.85 \pm 1.19$ \\
WC $(\mathrm{cm})$ & $86.03 \pm 8.53$ & $84.36 \pm 8.33$ & $85.11 \pm 8.45$ \\
BMI $(\mathrm{kg} / \mathrm{m} 2)$ & $25.75 \pm 3.77$ & $24.76 \pm 3.53$ & $25.21 \pm 3.67$ \\
SBP $(\mathrm{mm} \mathrm{Hg})$ & $114.13 \pm 11.73$ & $114.74 \pm 11.47$ & $114.47 \pm 11.58$ \\
DBP $(\mathrm{mm} \mathrm{Hg})$ & $75.12 \pm 8.77$ & $75.92 \pm 8.77$ & $75.56 \pm 8.77$ \\
\hline
\end{tabular}

WC: Waist Circumference, BMI: Body Mass Index, SBP: Systolic Blood Pressure; DBP: Diastolic Blood Pressure. 
Table 2. Prevalence of risk assessment factors of IDRS for developing type 2 diabetes among Bangladeshi subjects $(\mathrm{n}=602)$

\begin{tabular}{|c|c|c|c|c|c|}
\hline \multicolumn{2}{|l|}{ Risk Assessment Factors of IDRS } & $\begin{array}{l}\text { Male } \\
\mathrm{N}(\%) \\
\end{array}$ & $\begin{array}{l}\text { Female } \\
\mathrm{N}(\%) \\
\end{array}$ & $\begin{array}{l}\text { Total } \\
\mathrm{N}(\%)\end{array}$ & $\mathrm{p}$ value \\
\hline \multirow{4}{*}{ Age (yrs) } & $<35$ Years & $124(20.6)$ & $147(24.4)$ & $271(45.0)$ & \multirow[b]{2}{*}{0.390} \\
\hline & 35-49 Years & $87(14.5)$ & $122(20.3)$ & $209(34.7)$ & \\
\hline & $\geq 50$ Years & $60(10.0)$ & $62(10.3)$ & $122(20.3)$ & \\
\hline & Less than $90 \mathrm{~cm}$ & $130(21.6)$ & & $130(21.1)$ & \multirow{2}{*}{0.000} \\
\hline \multirow{2}{*}{$\begin{array}{l}\text { Waist } \\
\text { Circumference (cm) }\end{array}$} & $\geq 90-99 \mathrm{~cm}$ & $113(18.8)$ & & $113(18.8)$ & \\
\hline & $\geq 100 \mathrm{~cm}$ & $28(4.7)$ & & $28(4.7)$ & \\
\hline \multirow[t]{3}{*}{ Female } & Less than $80 \mathrm{~cm}$ & & $97(16.1)$ & $97(16.1)$ & \multirow{3}{*}{0.000} \\
\hline & $80-89 \mathrm{~cm}$ & & $131(21.8)$ & $131(21.8)$ & \\
\hline & $\geq 90 \mathrm{~cm}$ & & $103(17.1)$ & $103(17.1)$ & \\
\hline \multirow[t]{4}{*}{ Physical Activity (30 min daily) } & $\begin{array}{l}\text { Regular Vigorous } \\
\text { Exercise }\end{array}$ & $1(0.2)$ & $0(0.0)$ & $1(0.2)$ & \multirow{4}{*}{0.048} \\
\hline & $\begin{array}{l}\text { Regular Moderate } \\
\text { Exercise }\end{array}$ & $81(13.5)$ & 70 (11.6) & $151(25.1)$ & \\
\hline & Regular Mild Exercise & $108(17.9)$ & $158(26.2)$ & $266(44.2)$ & \\
\hline & No Exercise & $81(13.5)$ & $103(17.1)$ & $184(30.6)$ & \\
\hline \multirow[t]{3}{*}{ Family History of Diabetes } & No Diabetes in Parents & $142(23.6)$ & $163(27.1)$ & $305(50.7)$ & \multirow{3}{*}{0.384} \\
\hline & One Parent is Diabetic & $83(13.8)$ & $97(16.1)$ & $180(29.9)$ & \\
\hline & $\begin{array}{l}\text { Both Parents are } \\
\text { Diabetic }\end{array}$ & $46(7.6)$ & $71(11.8)$ & $117(19.4)$ & \\
\hline
\end{tabular}

IDRS: Indian Diabetes Risk Score; Pearson chi-square test was done; P value $<0.05$ is significant. 
Table 3. Prevalence of risk assessment factors of ADA risk score for developing type 2

diabetes among Bangladeshi subjects $(n=602)$.

\begin{tabular}{|c|c|c|c|c|c|}
\hline \multicolumn{2}{|c|}{$\begin{array}{l}\text { Risk Assessment Factors for ADA Risk } \\
\text { Score }\end{array}$} & $\begin{array}{l}\text { Male } \\
\mathrm{N}(\%)\end{array}$ & $\begin{array}{l}\text { Female } \\
\mathrm{N}(\%)\end{array}$ & $\begin{array}{l}\text { Total } \\
\mathrm{N}(\%)\end{array}$ & $\mathrm{p}$ value \\
\hline \multirow[t]{4}{*}{ Age (yrs) } & $<40$ Years & $147(24.4)$ & $209(34.7)$ & $356(59.1)$ & \multirow{4}{*}{0.042} \\
\hline & 40-49 Years & $59(9.8)$ & $62(10.3)$ & $121(20.1)$ & \\
\hline & 50-59 Years & $38(6.3)$ & $44(7.3)$ & $82(13.6)$ & \\
\hline & $\geq 60$ Years & $27(4.5)$ & $16(2.7)$ & $43(7.1)$ & \\
\hline \multirow[t]{2}{*}{ History of GDM } & Yes & & $62(18.73)$ & $62(18.73)$ & \multirow{2}{*}{0.000} \\
\hline & No & & $269(81.26)$ & $269(81.26)$ & \\
\hline \multirow{2}{*}{$\begin{array}{l}\text { Family History of Diabetes } \\
\text { Mellitus }\end{array}$} & Yes & $148(24.6)$ & $179(29.7)$ & $327(54.3)$ & \multirow{2}{*}{0.896} \\
\hline & No & $123(20.4)$ & $152(25.2)$ & $275(45.7)$ & \\
\hline \multirow{2}{*}{$\begin{array}{l}\text { History of Hypertension/ } \\
\text { High Blood Pressure }\end{array}$} & Yes & $71(11.8)$ & $72(12.0)$ & $143(23.8)$ & \multirow{2}{*}{0.202} \\
\hline & No & $200(33.2)$ & $259(43.0)$ & $459(76.2)$ & \\
\hline \multirow[t]{2}{*}{ Daily Physical Activity } & Yes & $89(14.8)$ & $87(14.5)$ & $176(29.2)$ & \multirow{2}{*}{0.078} \\
\hline & No & $182(30.2)$ & $244(40.5)$ & $426(70.8)$ & \\
\hline \multirow[t]{4}{*}{$\begin{array}{l}\text { Weight Category; } \\
\text { (BMI: } \mathrm{kg} / \mathrm{m} 2 \text { ) }\end{array}$} & $\begin{array}{l}\text { Normal Weight } \\
(<25 \mathrm{~kg} / \mathrm{m} 2)\end{array}$ & $98(16.3)$ & $158(26.2)$ & $256(42.5)$ & \multirow{4}{*}{0.023} \\
\hline & $\begin{array}{l}\text { Overweight } \\
(25-<30 \mathrm{~kg} / \mathrm{m} 2)\end{array}$ & $128(21.3)$ & $134(22.3)$ & $262(43.5)$ & \\
\hline & $\begin{array}{c}\text { Obese } \\
(>30-<40 \mathrm{~kg} / \mathrm{m} 2)\end{array}$ & $42(7.0)$ & $38(6.3)$ & $80(13.3)$ & \\
\hline & $\begin{array}{c}\text { Morbid Obese } \\
(\geq 40 \mathrm{~kg} / \mathrm{m} 2)\end{array}$ & $3(0.5)$ & $1(0.2)$ & $4(0.7)$ & \\
\hline
\end{tabular}

ADA: American Diabetes Association; BMI: body mass index; GDM: Gestational Diabetes Mellitus. Pearson chi-square test was done; $\mathrm{p}<0.05=$ significant. 
Table 4. Prevalence of risk assessment factors of FINDRISC for developing type 2 diabetes among Bangladeshi subjects $(\mathrm{n}=602)$

\begin{tabular}{|c|c|c|c|c|c|c|}
\hline \multicolumn{3}{|c|}{ Risk assessment factors of FINDRISC } & $\begin{array}{c}\text { Male } \\
{[\mathrm{N}(\%)]}\end{array}$ & $\begin{array}{l}\text { Female } \\
{[\mathrm{N}(\%)]}\end{array}$ & $\begin{array}{c}\text { Total } \\
{[\mathrm{N}(\%)]}\end{array}$ & $\begin{array}{c}\mathrm{p} \\
\text { value }\end{array}$ \\
\hline \multirow{4}{*}{\multicolumn{2}{|c|}{ Age (yrs) }} & $<45$ Years & $185(30.7)$ & $229(38.0)$ & $414(34)$ & \multirow{4}{*}{0.933} \\
\hline & & 45-54 Years & $49(8.1)$ & $55(9.1)$ & $104(17.3)$ & \\
\hline & & 55-64 Years & $31(5.1)$ & $41(6.8)$ & $72(12.0)$ & \\
\hline & & $>64$ Years & $6(1.0)$ & $6(1.0)$ & $12(2.0)$ & \\
\hline \multirow{3}{*}{\multicolumn{2}{|c|}{$\begin{array}{l}\text { Family history of diabetes } \\
\text { mellitus }\end{array}$}} & No & 88 (14.6) & $104(17.3)$ & $192(31.9)$ & \multirow{3}{*}{0.903} \\
\hline & & $\begin{array}{c}\text { Grand Parent, aunt, uncle, } \\
\text { or first cousin }\end{array}$ & $57(9.5)$ & $167(11.1)$ & $124(20.6)$ & \\
\hline & & Parent, sibling, children & $126(20.9)$ & $160(26.6)$ & $286(47.5)$ & \\
\hline \multirow{3}{*}{\multicolumn{2}{|c|}{$\mathrm{BMI}(\mathrm{kg} / \mathrm{m} 2)$}} & $\begin{array}{l}\text { Normal: Lower than } \\
25 \mathrm{~kg} / \mathrm{m} 2\end{array}$ & $125(20.8)$ & $169(28.1)$ & $294(48.8)$ & 0.422 \\
\hline & & \multirow{2}{*}{$\begin{array}{l}\text { Over weight: } 25-30 \mathrm{~kg} / \mathrm{m} 2 \\
\text { Obese: Higher than } 30 \\
\mathrm{~kg} / \mathrm{m} 2\end{array}$} & \multirow{2}{*}{$\begin{array}{c}108(17.9) \\
38(6.3)\end{array}$} & \multirow{2}{*}{$\begin{array}{l}124(20.6) \\
38(6.3)\end{array}$} & \multirow{2}{*}{$\begin{array}{l}232(38.5) \\
76(12.6)\end{array}$} & \\
\hline & & & & & & \\
\hline \multirow{6}{*}{$\begin{array}{l}\text { Waist } \\
\text { circumference }(\mathrm{cm})\end{array}$} & \multirow{3}{*}{ Male } & Less than $94 \mathrm{~cm}$ & \multicolumn{2}{|l|}{$200(33.2)$} & $200(33.2)$ & \multirow{3}{*}{0.000} \\
\hline & & $94-102 \mathrm{~cm}$ & $53(8.8)$ & & $53(8.8)$ & \\
\hline & & More than $102 \mathrm{~cm}$ & $18(3.0)$ & & $18(3.0)$ & \\
\hline & \multirow[t]{3}{*}{ Female } & Less than $80 \mathrm{~cm}$ & & $128(21.3)$ & $128(21.3)$ & \multirow{3}{*}{0.000} \\
\hline & & $80-88 \mathrm{~cm}$ & & $120(19.9)$ & $120(19.9)$ & \\
\hline & & More than $88 \mathrm{~cm}$ & & $83(13.8)$ & $83(13.8)$ & \\
\hline \multirow{2}{*}{\multicolumn{2}{|c|}{$\begin{array}{l}\text { Physical activity } \\
\text { (at least } 30 \text { min daily) }\end{array}$}} & Yes & $192(31.9)$ & $235(39.0)$ & $427(70.9)$ & \multirow[t]{2}{*}{0.968} \\
\hline & & No & $79(13.1)$ & $96(15.9)$ & $175(29.1)$ & \\
\hline \multirow{2}{*}{\multicolumn{2}{|c|}{$\begin{array}{l}\text { Vegetables, fruit or berry } \\
\text { consumption }\end{array}$}} & Every day & $162(26.9)$ & $219(36.4)$ & $381(63.3)$ & \multirow[t]{2}{*}{0.106} \\
\hline & & Not every day & $109(18.1)$ & $112(18.6)$ & $221(36.7)$ & \\
\hline \multirow{2}{*}{\multicolumn{2}{|c|}{ History of hypertension }} & Yes & $69(11.5)$ & $69(11.5)$ & $138(22.9)$ & \multirow[t]{2}{*}{0.180} \\
\hline & & No & $202(33.6)$ & $262(43.5)$ & $464(77.1)$ & \\
\hline \multirow{2}{*}{\multicolumn{2}{|c|}{$\begin{array}{l}\text { History of previous high blood } \\
\text { glucose (i.e. IFG, IGT, GDM) }\end{array}$}} & Yes & $23(3.8)$ & $65(10.8)$ & 88 (14.6) & \multirow[t]{2}{*}{0.000} \\
\hline & & No & $248(41.2)$ & $266(44.2)$ & $514(85.4)$ & \\
\hline
\end{tabular}

BMI: Body Mass Index; IFG: Impaired Fasting Glucose; IGT: Impaired Glucose Tolerance; GDM: Gestational Diabetes Mellitus; FINDRISC: Finnish Diabetes Risk Score; Pearson chi-square test was done; P value $<0.05$ is significant. 


\section{Table 5: Comparison of the mean value of different risk score system for developing diabetes among subjects $(n=602)$}

\begin{tabular}{lcccccc}
\hline $\begin{array}{l}\text { Different Risk } \\
\text { Score System }\end{array}$ & $\begin{array}{c}\text { Male } \\
(\text { Mean } \pm \text { SD) }\end{array}$ & $\begin{array}{c}\text { Female } \\
(\text { Mean } \pm \text { SD) }\end{array}$ & $\begin{array}{c}\text { Total } \\
(\text { Mean } \pm S D)\end{array}$ & F & df & p value \\
\hline IDRS & $46.01 \pm 16.81$ & $51.29 \pm 19.99$ & $48.92 \pm 18.79$ & 11.98 & 1 & 0.001 \\
ADA & $3.70 \pm 1.69$ & $2.54 \pm 1.85$ & $3.06 \pm 1.87$ & 63.55 & 1 & 0.000 \\
FINDRISC & $7.33 \pm 4.19$ & $8.76 \pm 5.27$ & $8.12 \pm 4.86$ & 13.09 & 1 & 0.000 \\
\hline
\end{tabular}

ADA: American Diabetes Association; IDRS: Indian Diabetes Risk Score; FINDRISC: Finish Diabetes Risk Score; Pearson chi-square test was done; $\mathrm{P}$ value $<0.05$ is significant.

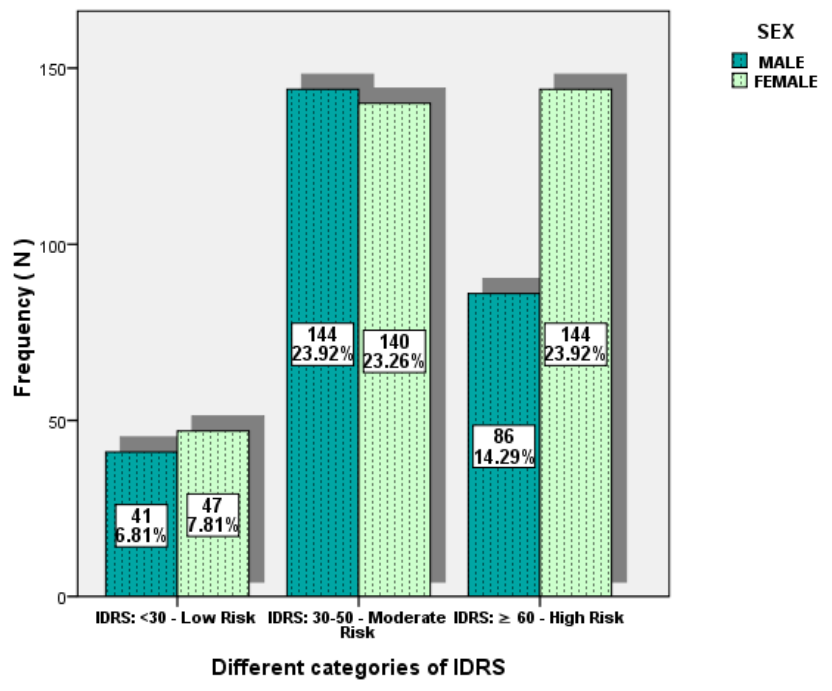

IDRS: Indian Diabetes Risk Score

Figure 1: Distribution of study subjects according to different categories of IDRS $(n=602)$

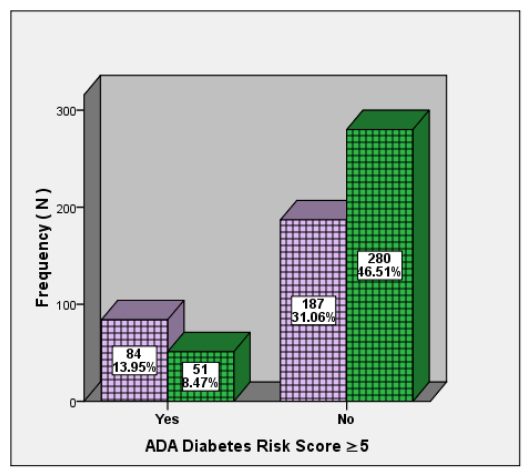

SEX
思 MALE
FEMAIE

ADA: American Diabetes Association

Figure 2: Different categories of ADA risk score among Bangladeshi subjects $(n=602)$ 


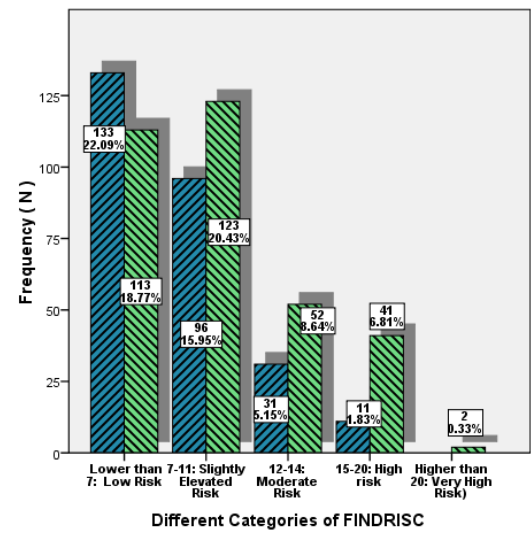

SEX
RALE
MFMALE

$\triangle$ FEMALE

Figure 3: Different categories of Finish diabetes risk score among Bangladeshi subjects

FINDRISC: Finish Diabetes Risk Score

Table 6. Comparison of risk score of developing diabetes using three different risk assessment tools in subjects $(n=602)$

\begin{tabular}{|c|c|c|c|c|c|c|}
\hline \multicolumn{3}{|c|}{ Risk Assessment Tools } & $\frac{\text { Male }}{[\mathrm{N}(\%)]}$ & $\begin{array}{c}\text { Female } \\
{[\mathrm{N}(\%)]}\end{array}$ & $\frac{\text { Total }}{[\mathrm{N}(\%)]}$ & $\mathrm{p}$ value \\
\hline \multirow[t]{3}{*}{ IDRS } & \multicolumn{2}{|l|}{ Low risk } & $41(6.8)$ & $47(7.8)$ & $88(14.6)$ & \multirow{2}{*}{0.010} \\
\hline & \multicolumn{2}{|c|}{ Moderate risk } & $144(23.9)$ & $140(23.3)$ & $284(47.2)$ & \\
\hline & \multicolumn{2}{|l|}{ High risk } & $86(14.3)$ & $144(23.9)$ & $230(38.2)$ & \\
\hline \multirow[t]{2}{*}{ ADA Risk Score } & \multirow[t]{2}{*}{$\begin{array}{l}\text { Risk score } \\
\geq 5\end{array}$} & Yes & $84(14.0)$ & $51(8.5)$ & $135(22.4)$ & \multirow{2}{*}{0.000} \\
\hline & & No & $187(31.1)$ & $280(46.5)$ & $467(77.6)$ & \\
\hline \multirow[t]{5}{*}{ FINDRISC } & \multicolumn{2}{|l|}{ Low risk } & $133(22.1)$ & $113(18.8)$ & $246(40.9)$ & \\
\hline & \multirow{2}{*}{\multicolumn{2}{|c|}{$\begin{array}{l}\text { Slightly elevated risk } \\
\text { Moderate risk }\end{array}$}} & $96(15.9)$ & $123(20.4)$ & $219(36.4)$ & \multirow[t]{2}{*}{0.000} \\
\hline & & & $31(5.1)$ & $52(8.6)$ & $83(13.8)$ & \\
\hline & \multicolumn{2}{|l|}{ High risk } & $11(1.8)$ & $41(6.8)$ & $52(8.6)$ & \\
\hline & \multicolumn{2}{|c|}{ Very high risk } & $0(0.0)$ & $2(0.3)$ & $2(0.3)$ & \\
\hline
\end{tabular}

IDRS: Indian Diabetes Risk Score; ADA: American Diabetes Association; FINDRISC: Finish Diabetes Risk Score; Pearson chi-square test was done; $\mathrm{P}$ value $<0.05$ is significant. 


\section{References}

1. Shaw JE, Sicree RA, Zimmet PZ. Global estimates of the prevalence of diabetes for 2010 and 2030. Diabetes Res Clin Pract. 2010; 87:4-14.

2. Chiasson JL, Josse RG, Gomis R, Hanefeld M, Karasik A, Laakso M.. Acarbose for prevention of type 2 diabetes mellitus: the STOP-NIDDM randomized trial. Lancet. 2002; 359(9323):2072-77.

3. Simmons RK, Echouffo-Tcheugui JB, Griffin SJ. Screening for type 2 diabetes: an update of the evidence. Diabetes, Obesity and Metabolism. 2010; 12:838-44.

4. World Health Organization, International Diabetes Federation. Definition and Diagnosis of Diabetes Mellitus and Intermediate Hyperglycemia: Report of a WHO/IDF Consultation. Geneva, Switzerland: World Health Organization; 2006.

5. Norris SL, Kansagara D, Bougatsos C, Fu R. Screening for type 2 diabetes: a review of the evidence for the U.S.Preventive Services Task Force. Ann Intern Med. 2008;148(11):855-68.

6. Lindstro“m J, Neumann A, Sheppard KE, Gilis-Januszewska A, Greaves CJ, Handke U, et al. Take action to prevent diabetesthe IMAGE toolkit for the prevention of type 2 diabetes in Europe. Horm Metab Res. 2010;421:S37-S55.

7. Ackermann RT, Marrero DG. Adapting the Diabetes Prevention Program lifestyle intervention for delivery in the community: the YMCA model. Diabetes Educ.2007; 33(1):69-78.

8. Kahn HS, Cheng YJ, Thompson TJ,Imperatore G, Gregg EW. Two risk-scoring systems for predicting incident diabetes mellitus in U.S. adults age 45 to 64 years. Ann Intern Med. 2009; 150:741-51.

9. Diabète de type 2: quell estvotrerisque? [Internet], 2011. Available from http://www.diabetesgesellschaft.ch/fr/informations/test-diabete/. Accessed 26 May 2011.

10. Mann DM, Bertoni AG, Shimbo D, Carnethon MR, Chen H, Jenny NS, et al. Comparative validity of 3 diabetes mellitus risk prediction scoring models in a multiethnic US cohort: the Multi-Ethnic Study of Atherosclerosis. Am J Epidemiol. 2010; 171:98088.

11. Mohiuddin AK. Diabetes Fact: Bangladesh Perspective. International Journal of Diabetes Research.2019; 2(1):14-20.

12. Herman WH, Smith PJ, Thompson TJ, Engelgau M, Aubert R.A. new and simple questionnaire to identify people at increased risk for undiagnosed diabetes. Diabetes Care. 1995; 18(3): 382-87.

13. Lindstrom J, Tuomilehto J. The diabetes risk score: a practical tool to predict type 2 diabetes risk. Diabetes Care.2003; 26: 725-31.

14. Glumer C, Jorgensen T, Borch-Johnsen K. Targeted screening for undiagnosed diabetes reduces the number of diagnostic tests. Diabet Med.2004; 21: 874-80.

15. Mohan V, Deepa R, Deepa M, Somannavar S, Datta M. A simplified Indian Diabetes Risk Score for screening for undiagnosed diabetic subjects. J Assoc of Physicians India.2005; 53: 759-63.

16. Poltavskiy E, Kim DJ, Bang H. Comparison of screening scores for diabetes and prediabetes. Diabetes Res Clin Pract. 2016; 118:14653.

17. National Institute for Health and Care Excellence. Preventing type 2 diabetes: risk identification and interventions for individuals at high risk. PH 38. London:NICE, 2012. http://www.nice.org.uk/guidance/ph38 (accessed 24 Sep 2015)

18. Latchan Z, Seereeram R, Kamalodeen A, Sanchez S, Deonarine U, Sinanan R, et al. TRAQ-D (Trinidad Risk Assessment Questionnaire for Type 2 Diabetes Mellitus): a cheap, reliable, non-invasive screening tool for diabetes. BrJ Diabetes Vasc Dis.2010; 10: 187-92.

19. Herman WH, Smith PJ, Thompson TJ, Engelgau MM, Aubert RE.A new and simple questionnaire to identify people at increased risk for undiagnosed diabetes. Diabetes Care. 1995; 18(3): 382-87. 
20. Smith Liz. New AHA recommendations for blood pressure measurement: American Heart Association Practice Guidelines. Am Fam Physician.2005; 72(7): 1391-98.

21. Mohan V, Sandeep S, Deepa M, Gokulakrishnan K, Datta M, Deepa R. A diabetes risk score helps identify metabolic syndrome and cardiovascular risk in Indians - the Chennai Urban Rural Epidemiology Study (CURES-38). Diabetes, obesity \& metabolism.2007; 9(3):337-43.

22. Bang H, Edwards A M, Bomback A S, Ballantyne CM, Brillon D, Callahan M A, et al. A patient self-assessment diabetes screening score: development, validation, and comparison to other diabetes risk assessment scores. Ann Intern Med. 2009; 151:775-83.

23. Latchan Z, Seereeram R, Kamalodeen A, Sanchez S, Deonarine U, Sinanan R, et.al. TRAQ-D (Trinidad Risk Assessment Questionnaire for Type 2 Diabetes Mellitus): a cheap, reliable, non-invasive screening tool for diabetes. Br J Diabetes Vasc Dis. 2010; 10: 187-92.

24. Herman WH. Predicting risk for diabetes: choosing the right model. Ann Intern Med. 2009;150(11):812-14.

25. Wolfgang R, Stephan M, Burkhard H, Andrea I, Rolf H, Hannelore L,et.al. Performance of Screening Questionnaires and Risk Scores for Undiagnosed Diabetes. Arch Intern Med. 2005; 165:436-41.

26. Gray BJ, Bracken RM, Turner D, Morgan K, Williams M, Rice S, et.al.Different type 2 diabetes risk assessments predict dissimilar numbers at 'high risk':a retrospective analysis of diabetes risk-assessment tools. $\mathrm{Br} J$ Gen Pract. 2015; http://doi.org/10.3399/bjgp15X687661. 